\title{
LA PRODUCCIÓN LÍTICA DEL YACIMIENTO NEOLÍTICO DE O REGUEIRIÑO (MOAÑA, PONTEVEDRA)
}

\author{
SOFIA BAQUEIRO VIDAL \\ Laboratorio de Arqueoloxía da Paisaxe, Instituto de Estudos Galegos Padre Sarmiento (CSIC-XuGa) \\ Unidade Asociada: Laboratorio de Paleoambiente, Patrimonio e Paisaxe (IIT, USC)
}

\section{Resumen}

Se analiza la producción lítica recuperada durante la intervención realizada en el yacimiento neolítico de O Regueiriño, concretando las bases teóricas y metodológicas como punto de partida.

\section{Palabras Clave}

Metodología de análisis, producción lítica tallada, producción lítica pulimentada, Neolítico, península de O Morrazo, área de actividad al aire libre.

\begin{abstract}
The lithic collection recovered in the recent archaeological excavations in the Neolithic site of O Regueiriño is analyzed in this paper, following a theoretical and methodological scheme that is previously presented.
\end{abstract}

\section{Key Words}

Analytical methodology, lithic production, lithic polished production, Neolithic, peninsula of O Morrazo, open air activity area. 


\section{EL YACIMIENTO DE O REGUEIRIÑO}

\subsection{Antecedentes}

El yacimiento de O Regueiriño, conocido desde mediados de los anos 70 del siglo pasado, fue objeto de sucesivas campañas de sondeo y se convirtió en un importante referente en la arqueología prehistórica gallega, a pesar de que la mayoría de los datos de las primeras intervenciones continúan todavía inéditos y apenas se han publicado algunas referencias (Peña 1985). Durante los últimos veinte años, la zona en la que se ubica el yacimiento ha sido sometida a innumerables alteraciones (una cantera, ampliación de una pista, repoblación forestal..) que han afectado de manera crítica al mismo.

Entre los meses de julio y octubre de 2003, en el marco del proyecto de construcción del Corredor de O Morrazo ${ }^{1}$, se llevó a cabo una intervención en el yacimiento, realizada por la empresa Adro Arqueolóxica y bajo la dirección de la arqueóloga Elena Lima Oliveira ${ }^{2}$.

Como consecuencia de esta intervención, fue recuperado un conjunto material de cuyo análisis se hizo cargo el Laboratorio de Arqueoloxía da Paisaxe del Instituto de Estudos Galegos Padre Sarmiento (IEGPS, CSIC, XuGa) (Prieto, Tabarés y Baqueiro 2005).

\subsection{Localización y contexto geológico}

El yacimiento de O Regueiriño está situado en el sector suroriental de la península de O Morrazo, al sur de la provincia de Pontevedra. Se encuentra emplazado en una serie de pequeños rellanos en la acusada ladera que desciende hacia la Ría de Vigo desde lo alto del Faro Domaio (Moaña), a unos 40 metros sobre el nivel del mar.

A nivel geológico, y desde una perspectiva de carácter regional, la zona se encuentra en parte de la terminación sur de la unidad denominada Fosa blastomi-

\footnotetext{
${ }^{1}$ Las actuaciones arqueológicas desarrolladas han de entenderse como un trabajo de corrección integral definido en el correspondiente Programa de Corrección do Impacto Arqueolóxico da construcción do Corredor do Morrazo. Ha sido planteada una estrategia conjunta que involucró a diversos agentes e instituciones bajo la coordinación de la CPTOPV y del Servicio de Arqueoloxía de la DXPC, la coordinación científica del Lar, y con una metodología de registro compartida, que permitió la colaboración de diferentes empresas y consultoras privadas de arqueología. Una síntesis de los resultados ha sido publicado en: Criado F. y Cabreras, E. (coord.) 2005. Obras Públicas e Patrimonio: Estudo Arqueológico do Corredor do Morrazo. TAPA (Traballos de Arqueoloxía e Patrimonio) 35. Santiago. Instituto de Estudos Galegos Padre Sarmiento (CSIC-Xunta de Galicia).

${ }^{2}$ La Memoria Técnica de dicha intervención fue depositada en la Dirección Xeral de Patrimonio Cultural con fecha 23 de julio de 2004.
} 


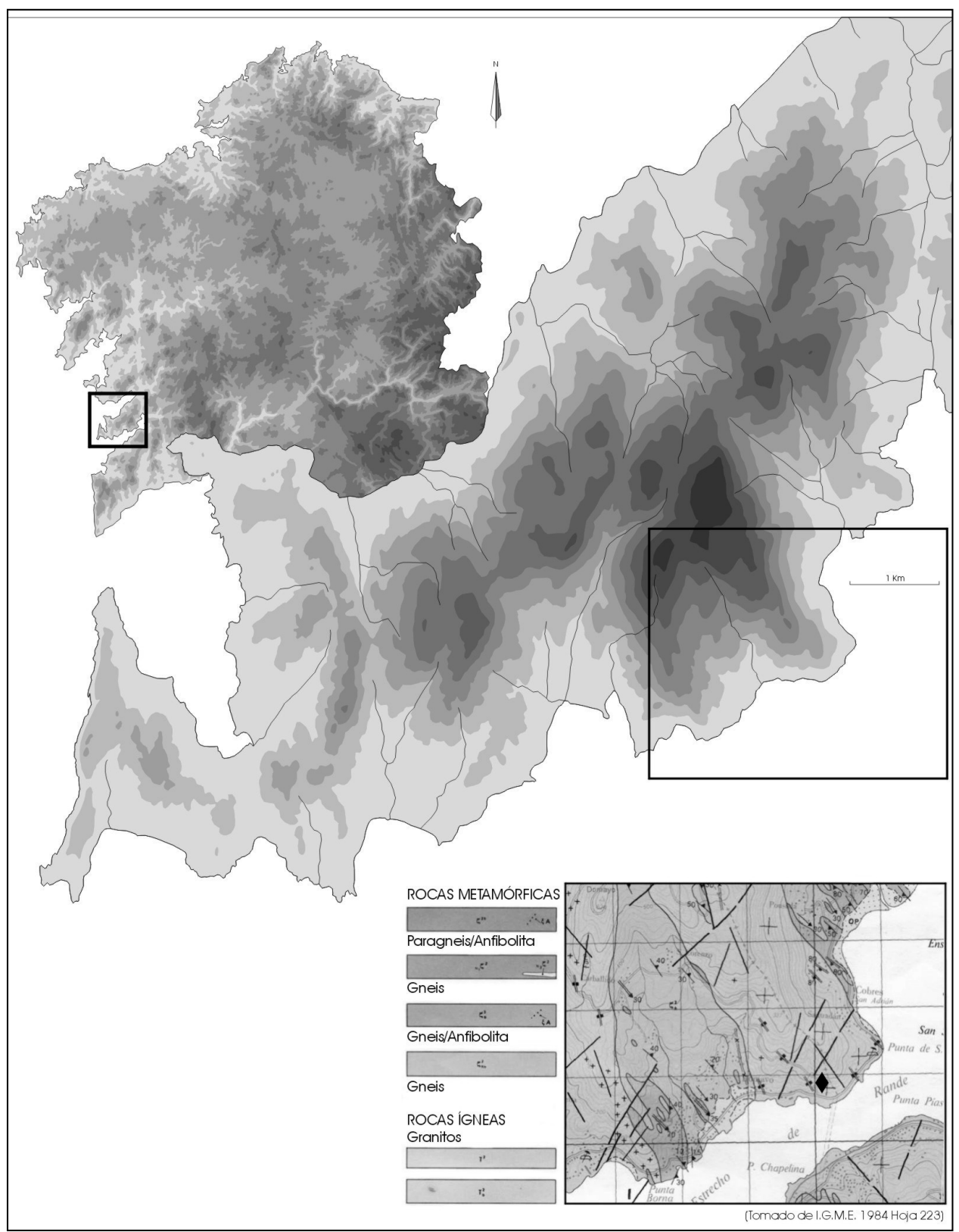

Figura 1. Localización del yacimiento dentro del contexto regional y local y mapa geológico de la zona en la que se ubica el yacimiento. 
lonítica, también denominada Unidad de Malpica-Tuy, dispuesta según una orientación submeridiana. Como substrato se encuentra un complejo metasedimentario en el que se han emplazado granitoides, actualmente ortogneises de naturaleza diversa (IGME 1981). El yacimiento de Regueiriño se ubica en un promontorio granítico entre dos bandas metamórficas (gneis, paragneis e intercalaciones de anfibolitas fundamentalmente).

\section{LA PRODUCCIÓN LÍTICA}

\subsection{Metodología de análisis}

Los conjuntos líticos recuperados en contexto arqueológico suponen una parte importante del registro material documentado. Estos restos, producto de la acción social pretérita, constituyen el resultado de toda una serie de procesos de trabajo que van desde la propia búsqueda y obtención de las materias primas, hasta la fabricación de los productos buscados, su utilización y su posterior abandono.

Partiendo de este hecho, el estudio de los conjuntos líticos debería estructurarse en torno a diferentes niveles de análisis, tales como: el análisis de la gestión y aprovisionamiento de la materia prima, el análisis de la producción, el análisis de la función y el análisis de la distribución espacial en el propio contexto en el que han sido recuperados. Esto se corresponde con el estudio de los diferentes procesos de trabajo llevados a cabo por una determinada comunidad, los cuales asimismo responden a los tres procesos inherentes a todo proceso productivo: la producción, el consumo y la distribución (Terradas 2001). Nosotros nos ocuparemos únicamente del análisis del proceso de producción lítica.

Para acometer el estudio de la producción a través de los restos líticos nos centraremos en el análisis de toda una serie de características, fundamentalmente de índole morfológica y tecnológica, que son las que definen a cada una de las piezas. Asimismo, y como procesos de fabricación diferenciados, trataremos por un lado la producción lítica tallada y, por otro, la producción pulida.

La metodología de análisis que proponemos y empleamos para la producción lítica tallada parte de los presupuestos teórico-metodológicos del Sistema Lógico Analítico, llevando a cabo una adaptación terminológica y centrándonos únicamente, y como ya hemos comentado, en un criterio de descripción desde una perspectiva morfotécnica.

En la producción tallada se han diferenciado, por un lado, los núcleos, y por otro los productos de lascado, esto es, lascas y láminas, a las que denominaremos 
soportes simples, los productos retocados, a los que hemos denominado soportes retocados y por último los desechos de talla.

En cuanto a la producción lítica pulimentada, hemos creído necesario diferenciar dos tipos de pulimento en la superficie de las piezas. De esta manera, por un lado hemos atendido a aquellas piezas que poseen pulimento fruto de la aplicación de la técnica de abrasión para formatizar y/o regularizar su superficie, de modo que la presencia de este pulimento parece responder a una intención. A estas piezas las hemos agrupado bajo la denominación de piezas con pulimento de fabricación. Por otro lado, hemos agrupado aquellas piezas cuyo pulimento podría ser el resultado de su participación en un proceso de trabajo que ha provocado la abrasión o pulimento de su superficie, y las hemos denominado como piezas con pulimento de uso.

Y por último bajo el epígrafe de otras producciones agruparemos todas aquellas piezas que no responden a ninguna de las categorías anteriormente mencionadas, si bien pueden presentar huellas de modificación antrópica, o su deposición no se debe a agentes naturales, por lo que se presupone que han sido aportados intencionalmente y por ello forman parte del registro lítico del yacimiento.

Los caracteres descriptivos que se han tenido en cuenta para analizar cada una de las piezas atañen fundamentalmente a dos esferas de análisis: por un lado, los caracteres formales y de composición, obtenidos a partir de su observación a un nivel macroscópico (materia prima, estado de conservación, alteraciones y medidas) y, por otro lado, los caracteres derivados de la observación de los rasgos y atributos tecnológicos existentes en la pieza, rasgos derivados de su participación en un proceso de talla, de pulimento, o bien simplemente su documentación en un contexto arqueológico.

\subsection{La producción lítica: características del conjunto}

El conjunto analizado está compuesto por un total de ciento veinticinco piezas que se reparten de manera desigual en las distintas categorías tecnomorfológicas y en las que se ha podido reconocer una variedad litológica bastante significativa.

Porcentualmente, el soporte litológico más representado es el de los materiales del grupo del cuarzo, que suponen algo más del $50 \%$ del total, destacando sus variedades cristalinas (cuarzo cristalino e hialino), así como un $26 \%$ de piezas de granito, también en diferentes variedades. El porcentaje restante se reparte de forma poco significativa en otra serie de materias primas, como son el sílex (6\%), la cuarcita $(5 \%)$ y otras como la pizarra, el gneis, la anfibolita o la turmalina. Asimismo, dos piezas presentan un soporte litológico que no ha podido ser identificado por 
medios macroscópicos ${ }^{3}$, debido fundamentalmente a que presentan un ligero pulimento que altera sus características superficiales y que por tanto impide su correcta asignación a un determinado tipo de materia prima.

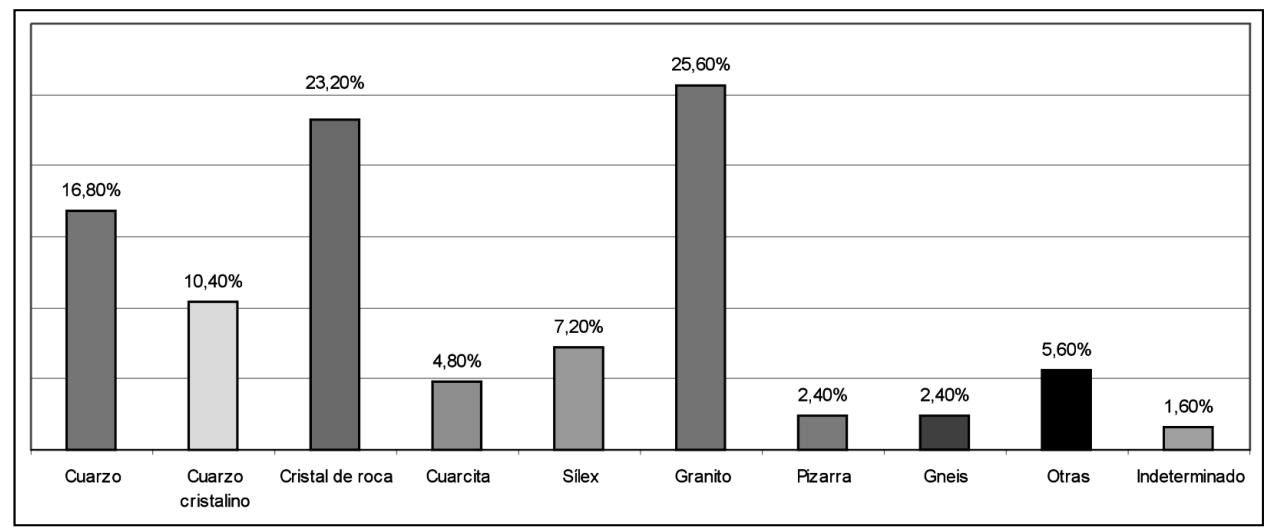

Figura 2. Porcentaje de materias primas documentadas.

Tal y como se observa en el gráfico adjunto, a nivel cualitativo la producción tallada supera a la pulida, aunque el grupo formado por las piezas que responden a otro tipo de producción también representan un porcentaje significativo.

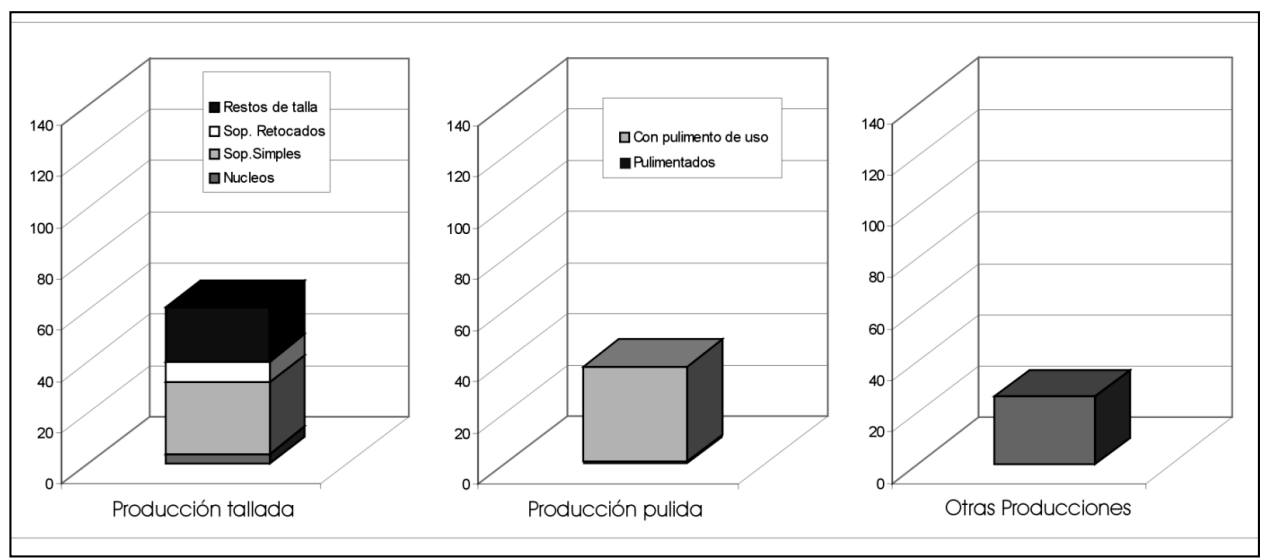

Figura 3. Representatividad de cada una de las categorías de análisis.

${ }^{3}$ Agradecemos la colaboración de la Dra. Carlota García Paz (profesora de Geología Ambiental de la Universidad de Santiago de Compostela) para la identificación geológica de algunas de las piezas. 
A nivel de conjunto, la categoría más representativa es la de las piezas con pulimento, que supone casi un $30 \%$ del total, seguido de los soportes simples, algo más del $23 \%$. El resto del porcentaje se reparte de manera desigual entre los desechos de talla (17\%), los soportes retocados (6\%) y los núcleos (que apenas suponen un $3 \%$ ). Finalmente, constatar que sólo se ha recuperado una pieza con pulimento de fabricación.

Por lo que respecta al estado de conservación, hemos anotado la existencia de una serie de alteraciones. Se trata de alteraciones de tipo físico (rodamiento y fracturas), químico (oxidación) y otro tipo de alteraciones, algunas de ellas de naturaleza no identificada (ver datos tabla y gráfico adjunto).

\begin{tabular}{|c|c|c|c|c|c|c|c|}
\hline \multicolumn{8}{|c|}{ ALTERACIONES } \\
\hline \multicolumn{4}{|c|}{ Físicas } & \multirow{2}{*}{\multicolumn{3}{|c|}{$\begin{array}{l}\text { Químicas } \\
\text { Oxidación }\end{array}$}} & \multirow{3}{*}{ Otras } \\
\hline \multicolumn{3}{|c|}{ Rodamiento } & \multirow{2}{*}{ Fracturas } & & & & \\
\hline Leve & Medio & Intenso & & Leve & Media & Intensa & \\
\hline- & 41 & 7 & \multirow{2}{*}{61} & 14 & 13 & - & 17 \\
\hline & 48 & & & \multicolumn{3}{|c|}{27} & \\
\hline
\end{tabular}

Figura 4. Cuantificación de alteraciones identificadas.

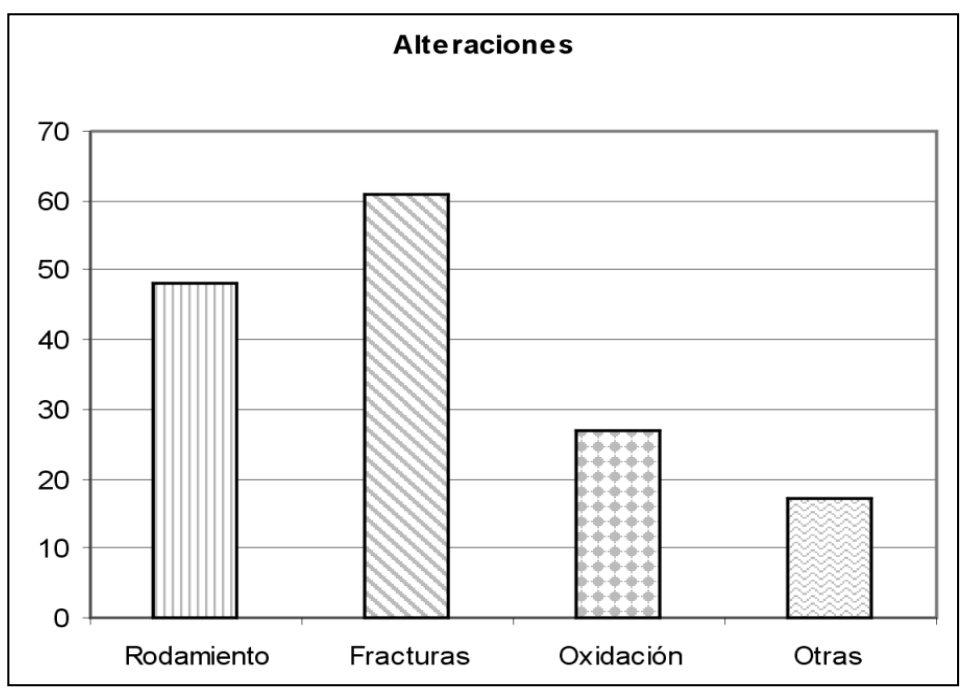

Figura 5. Principales alteraciones identificadas

En cuanto a las alteraciones físicas, hemos tenido en cuenta dos aspectos fundamentalmente: las huellas de rodamiento y la existencia de fracturas, atendiendo tanto a su orientación como a su localización en la pieza. 
El conjunto analizado presenta alteraciones físicas en algo más del $65 \%$ del total, predominando sobre todo la existencia de fracturas, en algo más del $48 \%$ del total. De estas fracturas, predominan las de tipo múltiple, que afectan a varias zonas de la pieza, seguidas de las fracturas de tipo transversal, oblicuas y longitudinales, respectivamente. Por otro lado, la presencia de huellas de rodamiento afecta a algo más del $48 \%$ del total, siendo éste de intensidad media fundamentalmente e intensa en apenas un $5 \%$ del total.

De la existencia de alteraciones de origen químico, solamente hemos atendido a la presencia de rasgos de oxidación y ésta se documenta en un $21 \%$ del total, de forma leve en un $11 \%$ y media en un $10 \%$ del total.

Hemos anotado también la presencia de otro tipo de alteraciones en las piezas, aunque su origen sea desconocido o no identificable. Estas alteraciones han sido documentadas en un $24 \%$ de las piezas, pudiendo identificar algunas como la presencia de cambios de coloración en la superficie o la presencia de termocúpulas (pequeñas extracciones de forma cóncava en la superficie de la pieza) ambas resultado de una alteración de tipo térmico.

\subsubsection{La producción lítica tallada}

La producción lítica tallada supone casi la mitad de la muestra documentada, en torno a un $49 \%$ del total, y las materias primas que sirven de soporte litológico a la misma se representan en el gráfico siguiente.

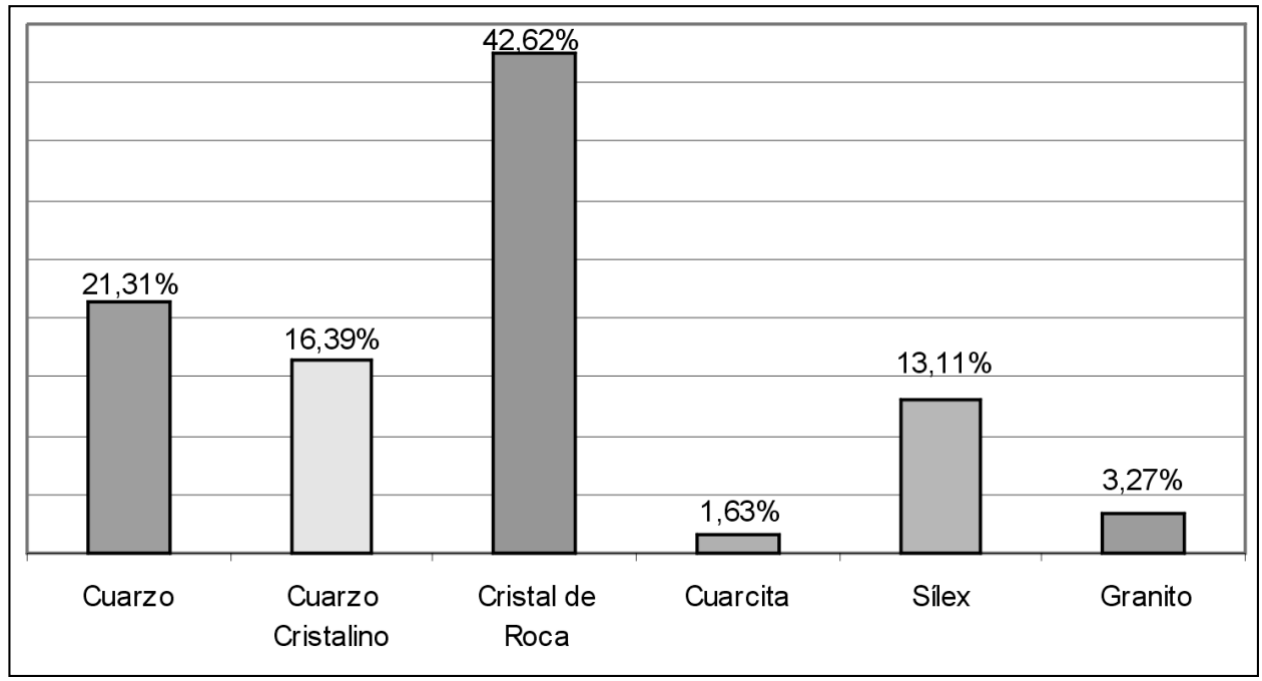

Figura 6. Soporte litológico de la producción tallada. 
Destaca el empleo de materias primas del grupo del cuarzo, sobre todo del cuarzo hialino o cristal de roca. Asimismo, se han documentado otras litologías, aunque de manera poco representativa, como el sílex, el granito o la cuarcita.

Para analizar la producción lítica tallada diferenciaremos por un lado los núcleos y, por otro, los productos de lascado, esto es, los soportes simples, los soportes retocados y los desechos de talla.

Tal y como se muestra en el gráfico siguiente, la documentación de núcleos es muy poco significativa, frente al grupo de los productos de lascado.

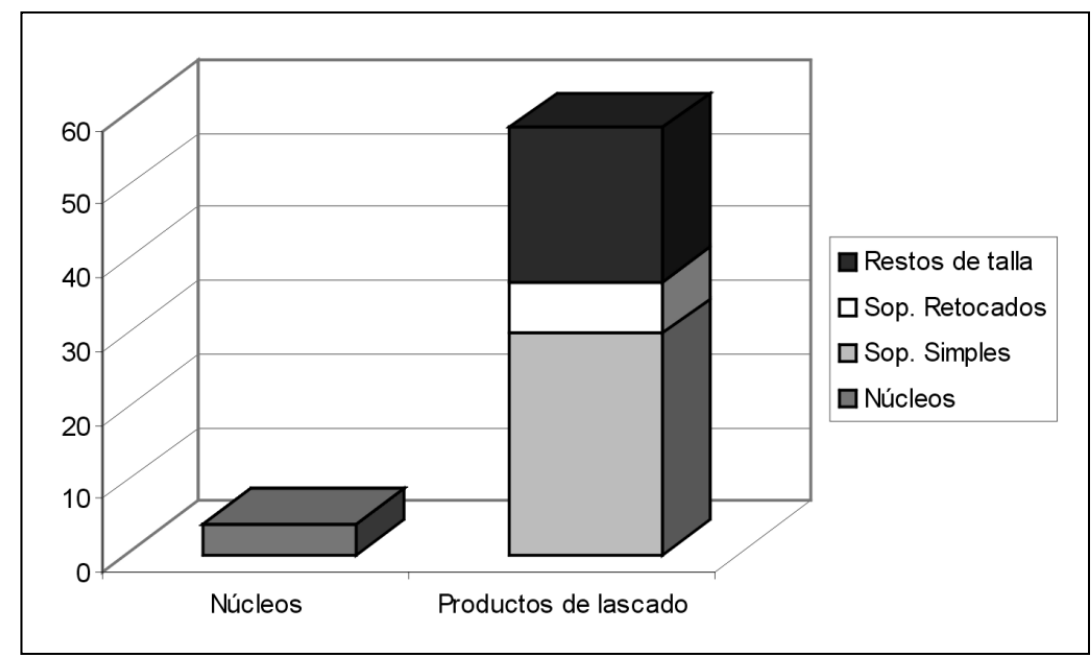

Figura 7. Categorías analíticas de la producción lítica tallada.

La categoría más representada es la de los soportes simples, que suponen un $49 \%$ del total de la producción tallada, seguida de los desechos de talla (en torno a un $34 \%)$. Completan el conjunto siete piezas formatizadas mediante retoque (11\%) y cuatro núcleos $(6 \%)$.

\section{LOS NÚCLEOS}

La metodología de análisis empleada para la descripción de los núcleos responde a la propuesta por X. Terradas (1995: 38-44). Apenas se han documentado cuatro piezas que puedan ser incluidas bajo este epígrafe, de las cuales una (REG.03/b0916) es de asignación antrópica dudosa.

En cuanto a la materia prima empleada, dos son de cuarzo (REG.03/b006 y REG.03/b0916), uno en una variedad cristalina, y los dos restantes en sílex, que 
atendiendo a sus características microscópicas, parece pertenecer a una variedad de sílex cuya formación estaría vinculada a un borde de filón de cuarzo, e incluso podría aventurarse un área-fuente similar (REG.03/b0324 y REG.03/b1362). El soporte sobre el que han sido realizados resulta indeterminable en todos los casos y ninguna de las piezas conserva restos de superficie cortical. Ambos presentan dos planos de interacción afectados por la explotación, y ésta se manifiesta de forma total, abarcando toda la cara explotada. Esta explotación se realiza mediante extracciones abruptas.

Los productos obtenidos a partir de estos núcleos sugieren una explotación tendente a la obtención de soportes simples tipo lasca y laminar. Asimismo, la pieza de cuarzo (REG03/0006) y una de las de sílex (REG03/1362) presentan negativos de extracción de morfología microlaminar.

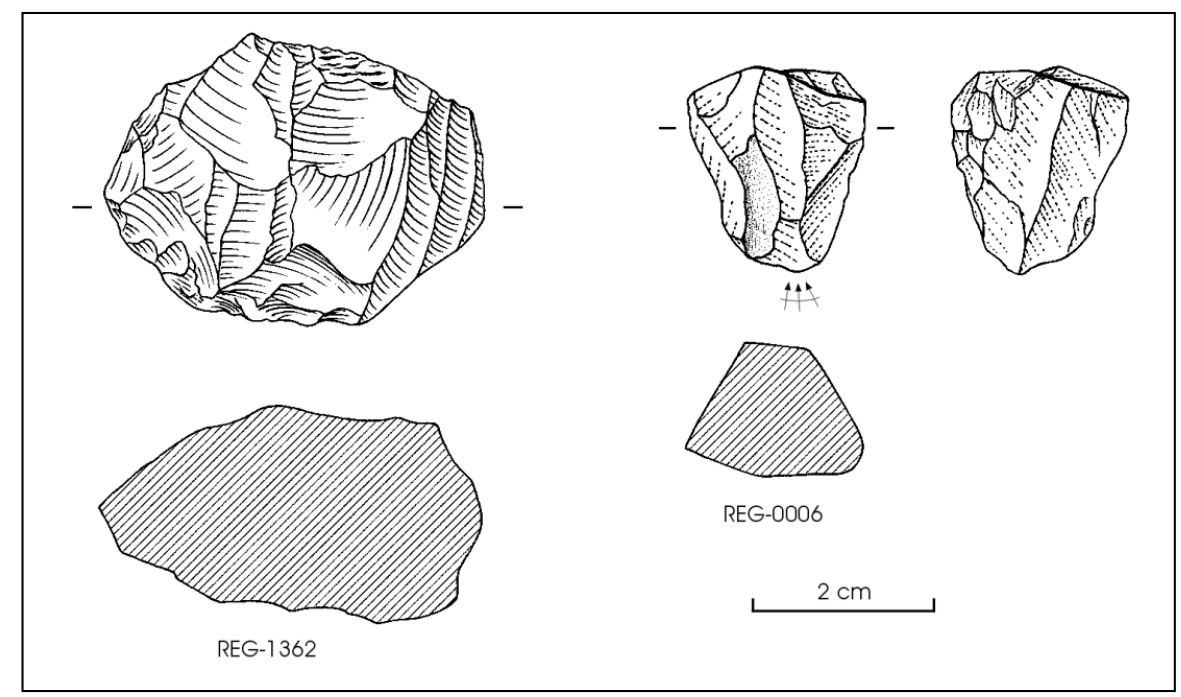

Figura 8. Ejemplo de núcleos documentados.

\section{LOS PRODUCTOS DE LASCADO}

Dentro de este grupo incluiremos aquellas piezas que se generan como consecuencia de un proceso de talla, esto es, los soportes simples, los soportes retocados y los desechos de talla. 


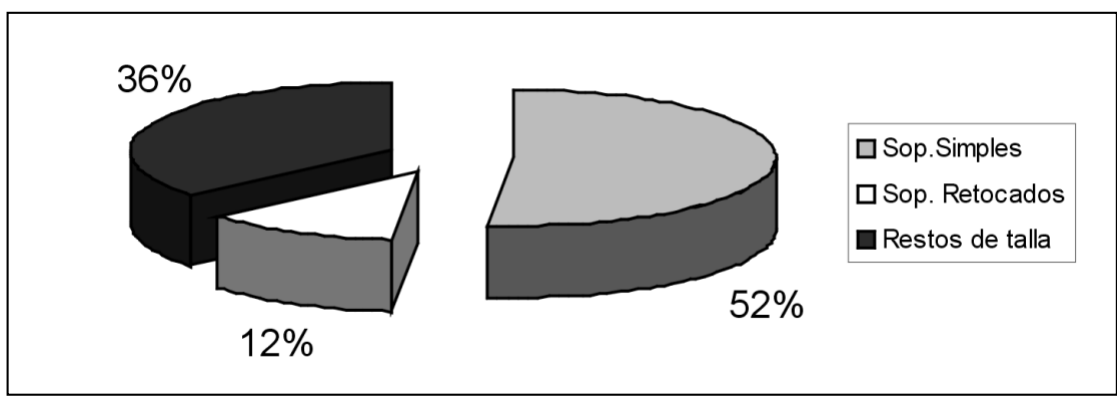

Figura 9. Representatividad de cada una de las categorías analíticas de los productos de lascado.

\section{a) Los soportes simples}

Denominaremos soporte simple a aquella pieza cuya características formales y tecnológicas permiten identificarla con lo que en las clasificaciones tradicionales al uso se ha denominado como lasca o lámina. Para la descripción y análisis de estos soportes simples, y atendiendo a las categorías definidas por el Sistema Lógico Analítico para las bases positivas, la pieza es analizada desde tres planos o caras diferentes que la definen como tal: cara dorsal o superior, cara ventral o inferior y cara talonar o plataforma de percusión. En cada una de estas caras se atiende a diferentes rasgos, unos formales y otros de carácter tecnológico (Mora, Martínez y Terradas 1991; Merino 1994).

Los soportes simples suponen, a nivel de conjunto, algo más del 23\%, y en relación a los productos de lascado un $53 \%$. Se trata de veintinueve piezas de las cuales catorce se corresponden con soportes laminares, siete de carácter micro, y las quince restantes son tipo lasca.

La materia prima predominante es la de los materiales del grupo del cuarzo, documentado en veintidós piezas, de las cuales catorce se corresponden con variedades cristalinas. Además, cuatro piezas han sido realizadas en sílex, una en cuarcita y las dos restantes en una variedad granítica de grano fino.

Las alteraciones que aparecen de forma generalizada en el conjunto de los soportes simples son fundamentalmente de origen físico, esto es, la presencia de fracturas $(48,3 \%)$. Estas fracturas son en la mayoría de los casos de carácter transversal y afectan a la parte distal de las piezas, aunque también se han documentado fracturas oblicuas o de carácter múltiple.

Los atributos que se han anotado en la cara dorsal de las piezas hacen referencia al grado de corticalidad, a la presencia o ausencia de levantamientos previos y a la presencia o ausencia de aristas. 
La gran mayoría de los soportes simples no presentan restos de superficie cortical en la cara dorsal, y en los que se ha podido observar, esta corticalidad se corresponde con soportes prismáticos en la mayoría. La presencia de córtex de soporte rodado ha sido documentada únicamente en dos piezas, en una lasca de decorticado y en una lámina, destacando el hecho de que ambas piezas se corresponden con el mismo tipo de materia prima, un granito de grano fino que parece presentar rasgos de alteración térmica.

Este predominio de la no corticalidad se traduce en la presencia de levantamientos previos en las caras dorsales, y por tanto en la presencia de aristas, lo que confirma la preparación de los planos de configuración del núcleo previa extracción de los soportes.

En el análisis de la cara talonar se han tenido en cuenta tres caracteres que se refieren al tipo de plataforma de percusión, así como a su morfología y delineación. Los talones que han podido reconocerse se corresponden con talones lineales en cinco casos, con plataformas o talones lisos en otros cinco, un talón facetado y otro puntiforme. En el resto de las piezas, los talones aparecen fracturados o no es posible identificarlos.

La existencia de talones lineales, y sobre todo machacados, parece indicarnos el empleo de la técnica de talla bipolar apoyada sobre yunque para la obtención de estos soportes. La aplicación de esta técnica sobre materiales del grupo del cuarzo permite optimizar las características de esta materia prima y por tanto obtener soportes con secciones finas y filos agudos (Prous 1986/1990: 99-100).

Las morfologías de las caras talonares que ha sido posible identificar se manifiestan muy variadas, apareciendo formas biconvexas, triangulares, trapezoidales, ovales y semicirculares. Y por lo que respecta a la delineación, ésta es generalmente rectilínea.

En la cara ventral o cara inferior se han anotado dos rasgos que también se refieren a la delineación y al tipo de bulbo que se manifiesta en dicha cara. Las delineaciones son fundamentalmente sinuosas y cóncavas, aunque también aparecen rectas y el tipo de bulbo no es posible reconocerlo en la gran mayoría de los casos $\mathrm{y}$ en los que aparece, se manifiesta de forma difusa. Solamente en cinco piezas se ha constatado la existencia de bulbo marcado.

Dentro de este conjunto debemos destacar algunas piezas, tanto en los soportes laminares como en los tipo lasca.

Los soportes laminares aparecen en su mayoría fracturados. La mitad de los efectivos son de carácter microlaminar, destacando una pieza realizada en cristal de roca y que es la que presenta un índice de anchura menor: $3 \mathrm{~mm}$ (REG.03/b0828). En cuanto a las láminas destaca una, realizada en sílex, de morfología seudotriangular 
y sección trapezoidal, con talón liso y bulbo difuso, en cuyos filos puede observarse la existencia de seudorretoques, posiblemente fruto de su uso, o bien se trata de leves retoques simples muy marginales ${ }^{4}$ (REG.03/b0937). Las características formales y tecnológicas de esta pieza apuntan a que ha podido ser obtenida mediante la técnica de talla directa con percutor blando de madera (Baena 1998:50).

Cabe señalar además dos piezas, también de sílex, de una variedad muy similar a la de la única pieza pulida del conjunto, que parecen consecuencia de la fractura de un mismo soporte laminar (REG.03/b1065 y REG.03/b1073).

En cuanto a las lascas, podemos destacar sobre el conjunto tres piezas en cuya cara dorsal predomina, o es total, la superficie cortical prismática (REG.03/b0143, REG.03/b0173 y REG.03/b1348). Destaca además una pieza realizada en sílex, de morfología triangular de base convexa, que podría asimilarse a una punta, aunque las extracciones que presenta en la cara dorsal son producto de una preparación anterior y no de retoque (REG.03/b0875).

\section{b) Los soportes retocados}

Solamente se han identificado siete soportes retocados, lo que apenas supone un $6 \%$ del total, y un $16 \%$ en relación a los productos de lascado.

Destaca la existencia de tres piezas de cristal de roca que conservan restos de superficie cortical prismática y que comparten características morfológicas y tecnológicas similares (REG03/0204, REG03/0252 y REG03/0719). Todas ellas presentan un soporte tipo lasca espesa, de morfología trapezoidal, con unas medidas que oscilan entre los 23 y $25 \mathrm{~mm}$ de longitud, 22 y $27 \mathrm{~mm}$ de anchura y entre 11 y $12 \mathrm{~mm}$ de espesor. Muestran la existencia de, al menos, un filo obtenido mediante retoques simples, bifaciales, profundos y de delineación denticulada. Son, como hemos anotado, formal y tipométricamente similares y la obtención de filos ha sido resuelta a nivel técnico de forma muy análoga en todas. Además, la reserva de superficie cortical que presentan nos habla de la predilección por este tipo de soportes y podría responder además a un hecho intencional y de carácter práctico y funcional para facilitar la sujeción y/o enmangue de la pieza.

Además de estas tres piezas, se han documentado otros cuatro soportes retocados, un fragmento de prisma de cristal de roca y tres piezas con soporte tipo lasca.

El prisma (REG03/0914) es de pequeño tamaño y poco espesor (medidas: 20/11/9 mm) y presenta señales de extracción microlaminares, profundas y bifaciales en un extremo, conformando un filo agudo.

\footnotetext{
${ }^{4}$ Esta imprecisión hace que la hayamos incluido en el grupo de los soportes simples y no en el de los retocados.
} 
En cuanto a los soportes tipo lasca, uno de ellos es de cuarcita de grano muy fino (REG03/0027), de morfología rectangular (medidas: 42/32/8 mm), y no conserva restos de superficie cortical. Presenta ambos extremos lineales y machacados de forma recurrente, caracteres implícitos al tipo de soporte obtenido mediante la técnica de talla bipolar sobre yunque (Prous 1986/1990, Curtoni 1996). En el borde derecho se puede apreciar levemente la existencia de retoque simple, muy marginal, directo y continuo. Este retoque podría sin embargo estar relacionado con los estigmas tecnológicos fruto de su fabricación y por tanto no ser consecuencia de una formatización posterior.

La otra pieza (REG03/0195), realizada sobre una pequeña lasca de cristal de roca (medidas: 16/12/5 mm), presenta un par de retoques semiabruptos, profundos, directos de delineación continua en la parte distal de la pieza, conformando un filo agudo. La pieza está fracturada en el extremo proximal y presenta seudorretoques en la zona del filo.

Por último, se ha documentado una pieza (REG03/0994) realizada sobre un soporte tipo lasca de cuarzo cristalino (medidas: 32/23/7 mm), de morfología trapezoidal. No conserva restos de superficie cortical y presenta un talón suprimido y un bulbo indeterminable. Presenta retoque simple, normal, muy marginal, directo y de delineación continua en los bordes.

\section{c) Desechos de talla}

En esta categoría se han incluido todas aquellas piezas en las que no es posible la identificación de los rasgos característicos de los soportes de lascado pero que muestran huellas de haber formado parte de un proceso de talla.

Los desechos de talla documentados suponen un $15 \%$ del total del conjunto y un $13 \%$ en relación a los productos de lascado. Son un total de veintiuna piezas y, de éstas, diecinueve están realizadas en variedades del cuarzo, sobre todo en su variedad más cristalina, el cristal de roca. Las dos piezas restantes son de sílex, en dos variedades diferentes.

Destaca el hecho de que, de los restos de talla realizados sobre variedades del cuarzo, al menos quince conservan restos de una superficie cortical prismática.

A nivel formal, la mayoría de estos desechos de talla son fundamentalmente esquirlas y pequeñas piezas lasquiformes, algunas de las cuales presentan pequeños filos agudos, susceptibles de haber sido empleados con una finalidad cortante (con presencia de leves seudorretoques).

Además, dos piezas se corresponden con acondicionamientos de la plataforma de percusión de un núcleo, uno realizado en cuarzo (REG03/0014) y otro en sílex (REG03/1241), de color beige claro. 


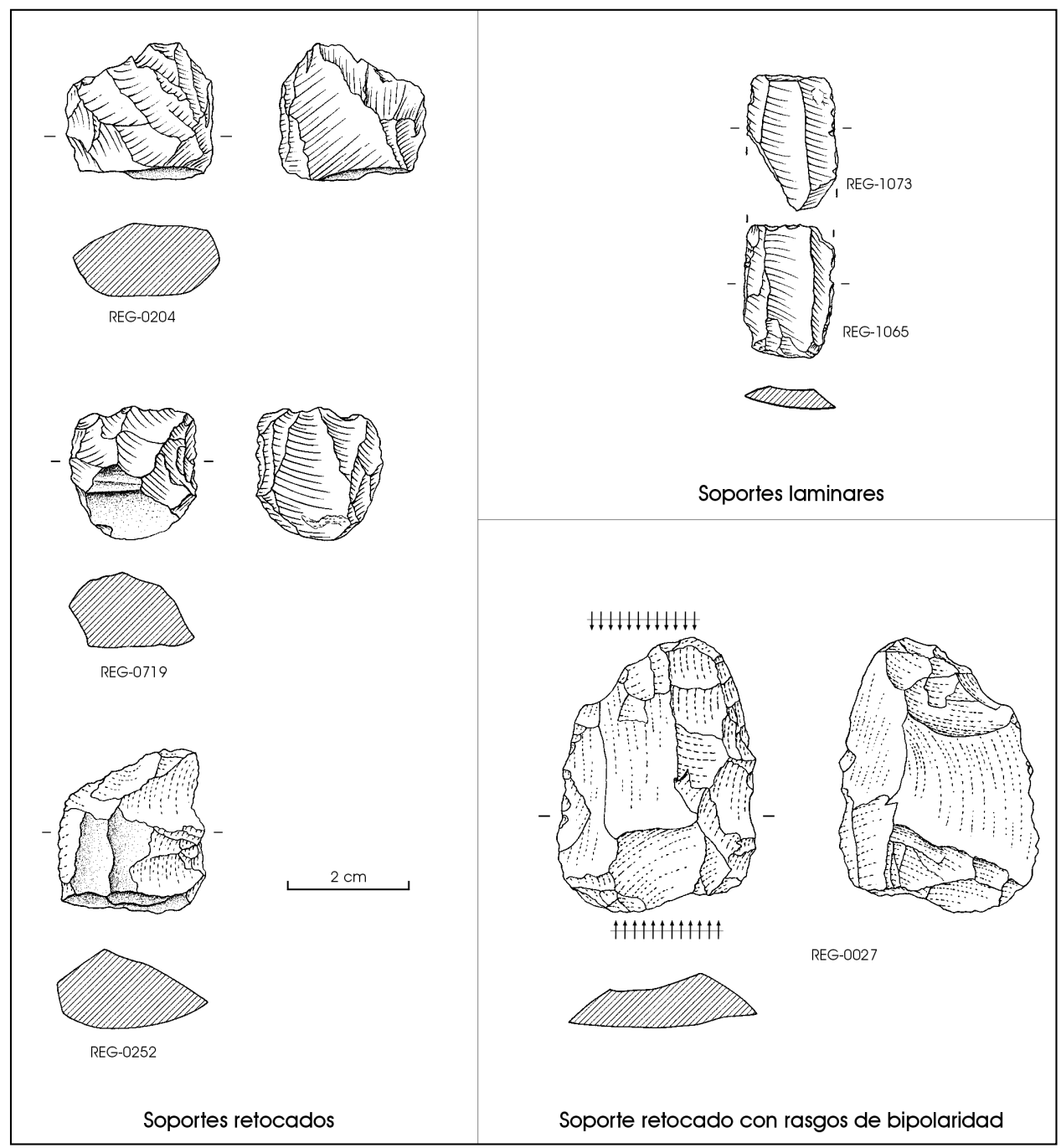

Figura 10. Soportes laminares y algunos de los soportes retocados más característicos.

\subsubsection{La producción lítica pulida}

La producción lítica pulida supone algo más del 30\% del total de la muestra analizada. En cuanto a la variedad litológica de los soportes pulidos, y tal y como se observa en el gráfico siguiente, el predominio del granito es absoluto. 


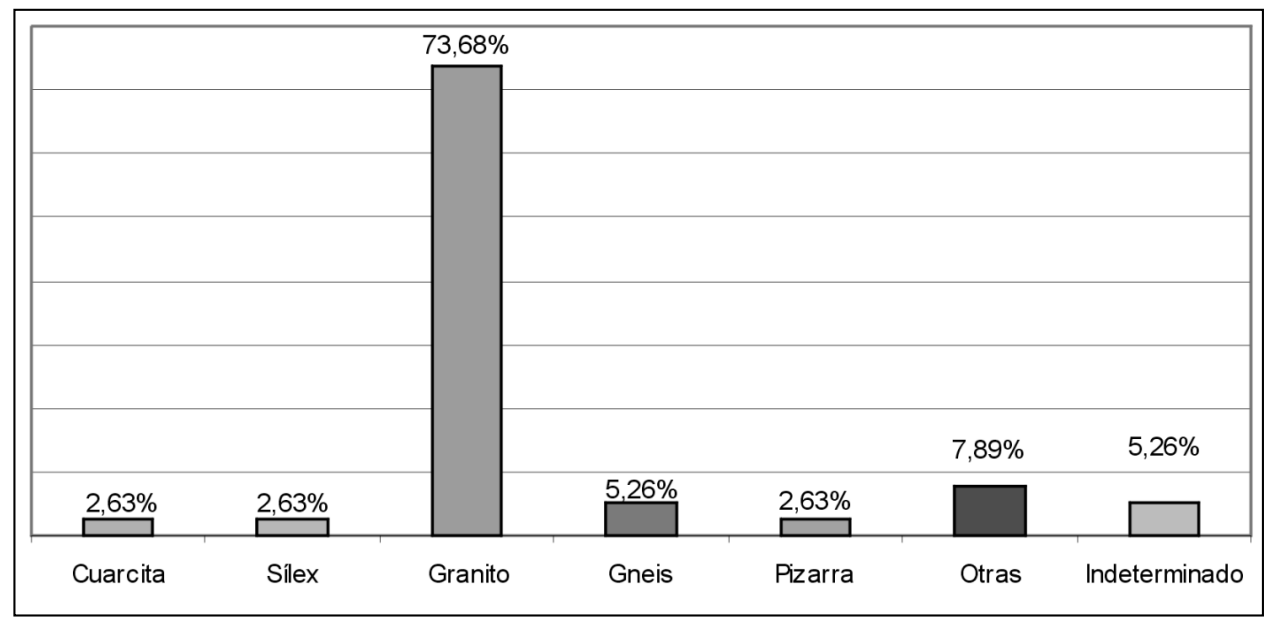

Figura 11. Soporte litológico de la producción pulida.

\section{LAS PIEZAS CON PULIMENTO DE USO}

Estas piezas suponen un importante porcentaje a nivel de conjunto, en torno a un $30 \%$ del total. Por lo que respecta al soporte litológico de este grupo de piezas, la materia prima predominante es el granito. Además, aparecen representados otros materiales como esquistos, gneis o cuarcita. Existen dos piezas cuyo soporte litológico no ha podido ser identificado debido a que el pulimento superficial que poseen desvirtúa sus características y su apariencia superficial desde un nivel de observación macroscópica.

Hemos intentado definir este grupo de piezas a partir del tipo de soporte, sus características formales y el lugar que ocupa el pulimento en la pieza. Teniendo en cuenta estas variables, las hemos agrupado en cinco grupos.

\section{a) Molinos}

Se trata de seis piezas espesas de granito, dos de ellas fracturadas, que parecen haber servido como soporte para la realización de labores de molienda. Todos los ejemplares son de granito y han sido realizados empleando un soporte tipo bloque, que en dos de los casos se corresponde con un soporte rodado. La asignación como molino de uno de los fragmentos es muy dudosa.

Los ejemplares que se conservan completos son, a nivel formal, bastante heterogéneos y el tamaño oscila entre los $70 \mathrm{~cm}$ de longitud del mayor a los $34 \mathrm{~cm}$ del 
menor y el espesor está en torno a los $15 \mathrm{~cm}$. Todos presentan una zona activa pulida de forma intensa, acentuándose en los ejemplares completos en la zona central. Esta zona activa no es en todos los casos rectilínea, sino que en ocasiones presenta cierta inclinación. Esta zona pulida destaca en una pieza (REG03/1342) en la que se ha formado una concavidad de unos $12 \mathrm{~cm}$ de diámetro y $1 \mathrm{~cm}$ de profundidad.

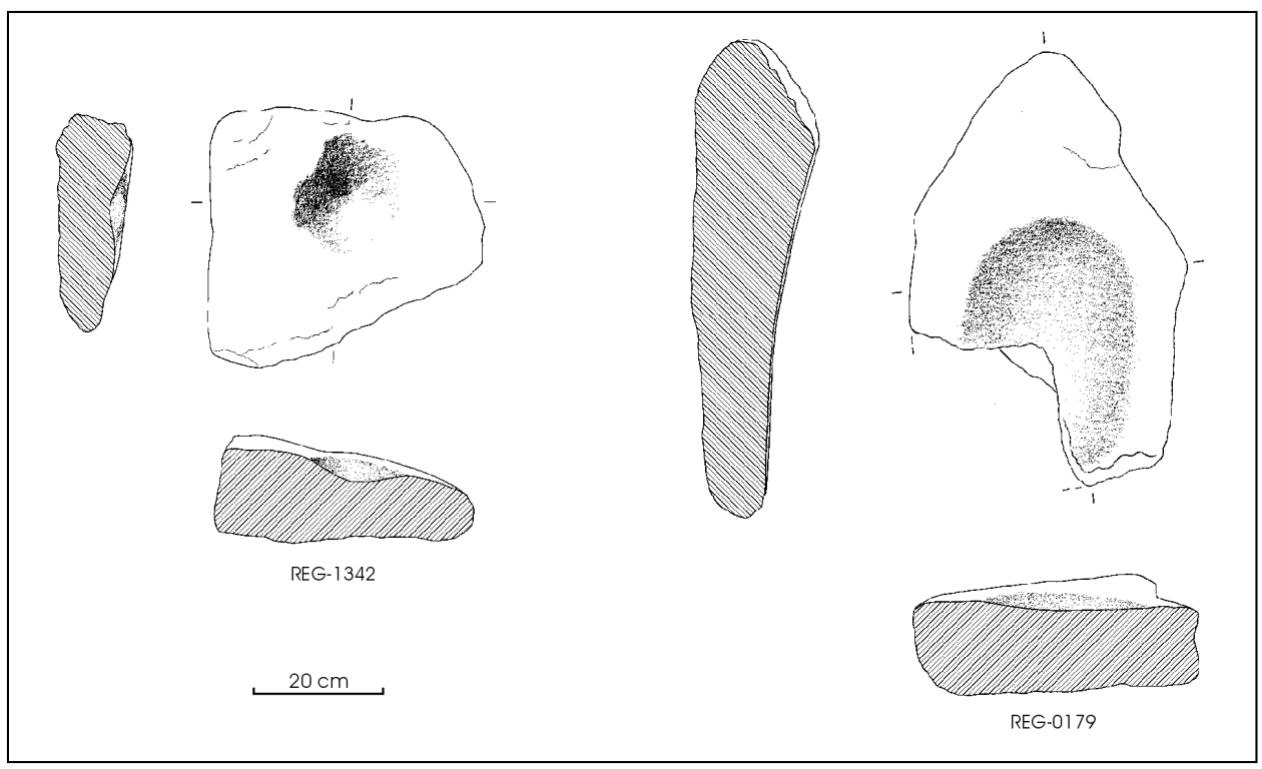

Figura 12. Algunos de los molinos documentados.

Sin la realización de análisis de residuos y/o de trazas de uso en estas piezas, no podemos plantear su posible utilización o funcionalidad, aunque teniendo en cuenta su heterogénea morfología y la disposición diferencial de las zonas más pulidas, parece que podrían haber sido empleados para labores de procesado de diversas materias. Tradicionalmente la documentación de este tipo de piezas en contextos arqueológicos ha sido tomada como un indicador de la existencia de labores agrícolas, lo cual ha de considerarse con cierta cautela, debido a la diversa funcionalidad que estos utensilios de molienda hayan podido tener y no exclusivamente de procesado de cereales, como se ha documentado en sociedades preagrícolas. Así, no sólo nos estamos refiriendo al procesado de materias primas orgánicas, tanto de origen animal como vegetal, o inorgánicas, como los minerales, sino que existe la posibilidad de que éstas piezas hayan podido servir como soporte para la regulari- 
zación de superficies en el proceso de fabricación de instrumentos pulidos. Si bien esta cuestión no ha sido abordada para el caso gallego, este hecho está documentado para toda la Europa Atlántica.

\section{b) Manos de molino}

Se han interpretado como posibles manos de molino veinticuatro piezas cuyos rasgos definitorios son los siguientes: soporte tipo canto rodado de granito, de morfología de tendencia ovalada y con, al menos, una de las caras planas en las que se observan marcas de pulimento. Destaca la existencia de rasgos de oxidación en la mayoría de las piezas, y además de constatar la existencia de una zona pulida, en algunas piezas se pueden observar marcas de picoteado en el contorno que se superponen al pulido. En cuanto al estado de conservación, solamente cuatro ejemplares están completos.

Entre todo el conjunto destaca una pieza (REG03/1108), un canto de granito de morfología ovalada y sección semicircular en cuya superficie cortical se conserva un somero pulimento, más acusado en la parte superior y en la cara plana. En el contorno presenta huellas de picoteado. Llama la atención la presencia de una pequeña oquedad ( $18 \mathrm{~mm}$ de diámetro y $5 \mathrm{~mm}$ de profundidad) casi en la parte central de la cara inferior plana. La materia prima presenta rasgos de alteración por oxidación. Podría tratarse de una mano de molino y/o una pieza relacionada con algún tipo de procesado específico. La documentación de este tipo de piezas resulta recurrente en yacimientos de la Prehistoria Reciente gallega, tal y como se ha constatado en Zarra de Xoacín 5 (Lalín, Pontevedra), A Devesa de Abaixo (Moaña, Pontevedra) (Prieto, Tabarés y Baqueiro 2005) o Montenegro (Moaña, Pontevedra) (Tabarés y Baqueiro 2005).

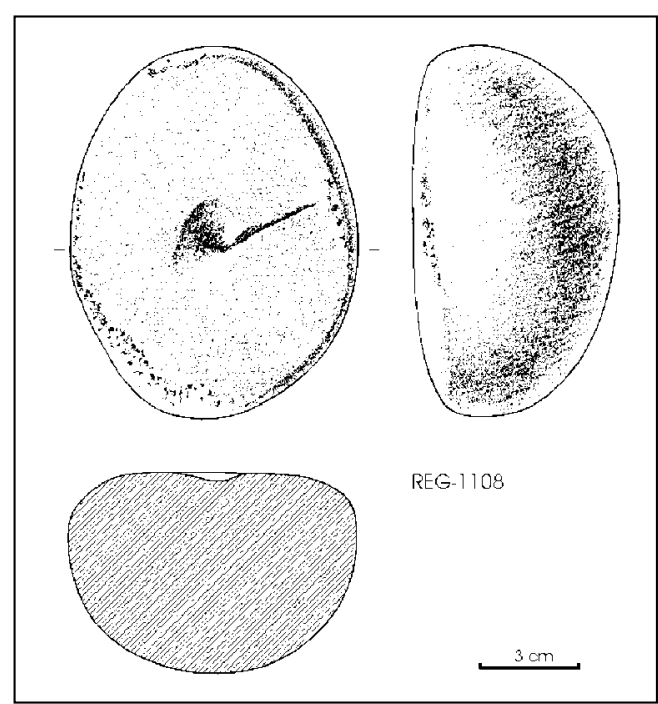

Figura 13. Mano de molino con oquedad central.

\footnotetext{
${ }^{5}$ La memoria de la intervención, dirigida por el arqueólogo Roberto Aboal Fernández, se encuentra actualmente en elaboración.
} 


\section{c) Plaquitas}

Se han documentado tres pequeñas piezas de materia prima esquistosa de muy poco espesor que parecen haber sido pulidas en toda su superficie. Destaca una (REG03/0792) de morfología seudorrectangular y sección muy fina que presenta seudorretoques en el borde más fino y el borde contrario, más espeso, aparece redondeado. En una de las caras, se observan unas pequeñas y leves incisiones con orientación transversal al filo, posibles marcas consecuencia del uso de la pieza.

\section{d) Pulidores}

Hemos anotado la posibilidad de que dos de las piezas documentadas hayan sido empleadas como pulidores.

Una de la piezas (REG03/0287) constituye un fragmento de soporte indeterminado de cuarcita carbonosa, de sección estrecha. La parte cortical conservada presenta un intenso pulimento en una de las caras, y en la contraria, aparece una banda de unos $17 \mathrm{~mm}$ de ancho a lo largo de la pieza, con un pulimento diferencial, formando una superficie ligeramente cóncava.

La otra pieza, un fragmento de granito (REG03/0758) de morfología y sección irregular, presenta una ligera concavidad que aparece intensamente pulida.

\section{e) Otras piezas}

Dentro de este grupo hemos incluido varias piezas. Por un lado, cuatro fragmentos de soportes indeterminados de anfibolita que presentan un intenso pulimento en la zona cortical que conservan. Estas piezas podrían haber funcionado a modo de mano de molino o pulidores, aunque el estado de fragmentación que presentan no permite aventurar ninguna asignación funcional. Además, existen otras dos piezas cuya materia prima no ha podido ser identificada y que presentan una parte de la superficie cortical pulida (REG03/0724 y REG03/1196). Una de ellas (REG03/1196) presenta algunos restos de una sustancia rojiza impregnada en la superficie, posiblemente ocre 6 .

\section{LAS PIEZAS CON PULIMENTO DE FABRICACIÓN}

Solamente se ha documentado una pieza (REG03/0411) que podría incluirse dentro de esta categoría. Se trata de un fragmento pulimentado que hemos tratado

\footnotetext{
${ }^{6}$ Durante la intervención en el yacimiento, fueron recuperados un total de treinta y tres fragmentos de ocre.
} 


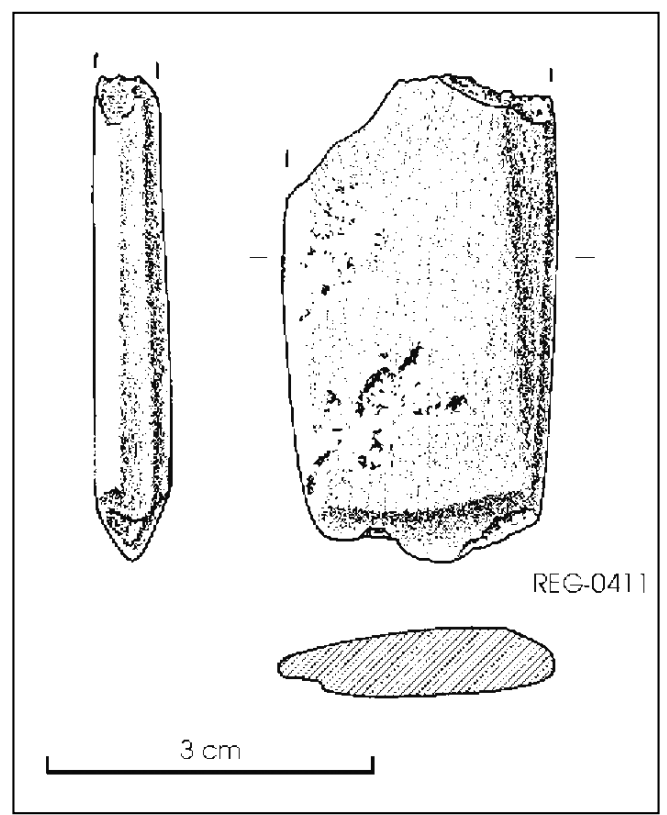

Figura 14. Fragmento de herramienta pulimentada. como fragmento distal teniendo en cuenta que conserva parte de un filo en un extremo, realizado sobre una materia prima silícea, posiblemente sílex filoniano. Presenta múltiples fracturas algunas levemente rodadas. Tiene unas dimensiones de $45 \times 25 \times 7$ $\mathrm{mm}$.

Muestra una morfología general de tendencia rectangular con una sección transversal muy fina de morfología seudorectangular de tendencia oval. La cara inferior es plana e irregular debido a las imperfecciones de la materia prima. El borde izquierdo es más espeso y redondeado que el derecho. En la zona distal, fracturada, se intuye la existencia de un filo convexo simétrico a doble bisel; convexo el de la cara superior y cóncavo el de la cara inferior. Por su parte, la zona activa es convexa asimétrica.

En toda la superficie de la pieza se puede observar a nivel microscópico la existencia de finas estrías, posiblemente fruto de la utilización de la pieza, o incluso del proceso de fabricación y cuya orientación es tanto transversal como longitudinal al eje mayor de la pieza en las caras y ligeramente oblicuas en la zona del borde más espeso y redondeado.
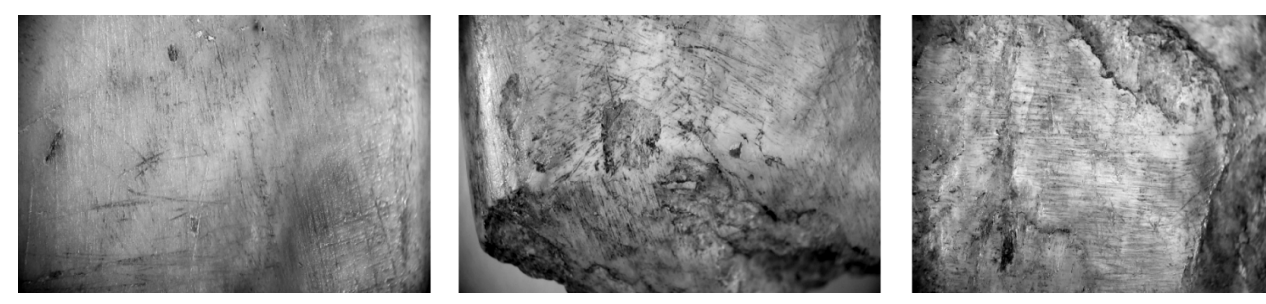

Figura 15. Microfotografías de diferentes zonas de la pieza en las que puede observarse la presencia de estrías ${ }^{7}$.

\footnotetext{
${ }^{7}$ Las microfotografías fueron tomadas con una lupa binocular Leika MZ7 5 .(20X).
} 
Teniendo en cuenta el estado de fragmentación de la pieza, enumeraremos a continuación los rasgos más destacables para intentar concluir una interpretación del tipo de instrumento del que se trata. Estos rasgos son:

- Poco espesor en relación a su anchura (A>2E ; 25>2x7).

- Sección transversal seudorrectangular.

- Cara superior biselada en el borde izquierdo.

- Filo convexo simétrico a doble bisel.

- Zona activa convexo-asimétrica.

Teniendo en cuenta estas características, sobre todo el primer y último extremo, y atendiendo a las descripciones de R. Fábregas (1984 y 1991), podríamos apuntar que la pieza bien podría ser el fragmento distal de una azuela del tipo IIb (definidas por poseer una zona activa asimétrica, anchura media y espesor muy reducido, con predominio de secciones rectangulares muy aplanadas) o el fragmento distal de una lámina de azada (caracterizadas por su gran longitud y anchura en relación a su espesor y presentan una zona activa convexo-simétrica). Ambos utensilios han sido tradicionalmente considerados como instrumentos de corte. Este autor añade que las azuelas del tipo IIb «poseen una gran similitud con las láminas de azada, de las que las separan la longitud desmesurada y el mejor acabado de estas últimas» (Fábregas 1991: 57). Por otro lado, las láminas de azada se caracterizan por su gran anchura en relación a su espesor y presentan una zona activa convexo simétrica. «El extraordinario alargamiento de las láminas de azada es, junto con el mejor acabado, la característica que las diferencia claramente de las azuelas tipo $\mathrm{IIb}$, con las que comparten rasgos morfológicos como el escaso espesor o el predominio de secciones transversales rectangulares» (Fábregas 1991: 65).

Teniendo en cuenta la similitud de rasgos y el estado de fragmentación de la pieza, resulta difícil asignarla a un tipo u otro de utensilio. En todo caso, la funcionalidad que se ha otorgado a este tipo de instrumentos ha sido tradicionalmente la de actividades de corte, tanto procesados de madera como labores agrícolas. Sin poder establecer ninguna conclusión sin llevar a cabo análisis de trazas de uso, podemos plantear la posibilidad de que esta pieza haya sido empleada para tareas menores teniendo en cuenta su reducido espesor y aparente fragilidad.

\subsubsection{Otras producciones}

Este grupo aparece bien representado en la muestra, suponiendo en torno a un $23 \%$ del total. Las diferentes piezas agrupadas bajo este epígrafe se corresponden mayoritariamente con dos grupos formales bien diferenciados, por un lado frag- 
mentos de cantos y soportes rodados de cuarzo y cuarcita y, por otro, las formas prismáticas.

\section{a) Cantos / fragmentos de soportes rodados}

Se han documentado trece piezas, de cuarzo y cuarcita, fragmentos de soportes rodados, en los que de manera sistemática aparecen los siguientes rasgos: la parte cortical conservada presenta un intenso grado de rodamiento, que podría en algunos casos corresponderse con un pulido de carácter intencional; muchos fragmentos de canto presentan una base plana y en algunas piezas aparecen huellas de extracción, e incluso melladuras.

Podemos plantear diferentes hipótesis interpretativas para este tipo de piezas. Por un lado, podría tratarse de fragmentos de cantos rodados empleados como percutores para la realización de actividades de talla. Otra opción podría plantear su aprovechamiento como núcleos para extracción de soportes, aunque las huellas de extracción existentes no parecen responder a dinámicas de talla sino más bien a extracciones fortuitas o fragmentos desprendidos. Y, por último, debido a que en muchos casos presentan superficies con un intenso rodamiento, en las cuales no es posible determinar si se trata de una superficie natural o de un pulido intencional o de uso, estas piezas podrían haber funcionado a modo de manos de molino, o elementos pulidores.

\section{b) Formas prismáticas}

Diez piezas se corresponden con prismas de cuarzo o cristal de roca. Destaca el hecho de que la mayoría presentan un grado de rodamiento bastante acusado. Todos los ejemplares son de tamaño medio, que oscila entre los $40 \mathrm{~mm}$ del mayor y los $11 \mathrm{~mm}$ del menor, con espesores variables en torno a los $12 \mathrm{~mm}$.

Cinco de ellos aparentemente no presentan huellas de modificación antrópica y los otros cinco presentan huellas de extracción, conformando en algunas piezas unos filos agudos susceptibles de haber sido empleados (REG03/0251, REG03/1022) o bien haber sido aprovechados como núcleos para extracción de pequeños soportes tipo lasca o lámina.

\section{Otras piezas}

Por último, destacaremos la presencia de cuatro piezas que no hemos incluido en ninguna de las categorías anteriores, por su singularidad y sobre todo porque la alteración superficial que presentan no nos permite discernir entre un rodamiento de carácter natural o bien un pulimento de carácter antrópico. Dos de estas piezas 
son de pizarra (REG03/0532 y REG03/109), una placa de pizarra filítica de sección fina y otra de pizarra carbonosa de morfología y sección trapezoidal. Las otras dos son de turmalina (REG03/0911 y REG03/0927).

\section{VALORACIÓN DE LA PRODUCCIÓN LÍTICA: REPRESENTATIVIDAD E IMPLICACIONES TECNOLÓGICAS}

Antes de realizar una valoración del conjunto lítico, volveremos sobre algunos de los rasgos generales que lo definen.

En primer lugar, debemos destacar la escasa representatividad numérica del mismo, ciento veinticinco piezas, sobre todo si tenemos en cuenta que el conjunto cerámico recuperado en la misma intervención asciende a un total de mil doscientas veintitrés piezas (Prieto, Tabarés y Baqueiro 2005a).

Esta escasez de la muestra lítica podría responder a un criterio de recogida selectiva durante la propia fase de excavación del yacimiento, teniendo en cuenta que las producciones líticas realizadas sobre materias primas del grupo del cuarzo presentan serias dificultades de identificación de los rasgos antrópicos por lo que, en ocasiones, los criterios de recogida son excesivamente selectivos y no generan una muestra lo suficientemente representativa, descartando en ocasiones un importante porcentaje de la muestra real. Este es un hecho que se constata a nivel general en la mayor parte de las intervenciones arqueológicas realizadas en el noroeste penínsular, y tiene mucho que ver con el desconocimiento de las mecánicas de fractura de los materiales del grupo del cuarzo y su empleo en dinámicas de talla de carácter antrópico.

Una vez anotado este hecho que nos parece relevante, llevaremos a cabo una revisión de aquellos aspectos que definen al conjunto.

Desde una perspectiva tecnológica, el conjunto de productos tallados supera al de los pulidos, aunque a nivel cualitativo el grupo de piezas que hemos agrupado bajo el epígrafe de otras producciones también supone un considerable porcentaje.

Tal y como se ha justificado en el apartado correspondiente, la variedad litológica que ha servido de soporte al conjunto parece estar representado por materiales de origen local, aunque podría darse alguna salvedad, como es el caso de algunos ejemplares silíceos, o el de las dos piezas cuyo soporte litológico no ha sido identificado.

En torno a la mitad de la muestra está realizada sobre diferentes variedades del grupo del cuarzo, sobre todo en sus variedades cristalinas. Este predominio se refiere más concretamente al grupo de los productos tallados, atendiendo a sus mejores cualidades para formar parte de un proceso de talla. El segundo material más repre- 
sentado es el del granito, y éste, por razones obvias, representa mayoritariamente al soporte litológico del conjunto pulimentado. Este hecho marca la existencia de un aprovisionamiento de materia prima diferencial según se trate del proceso de producción tallada o pulida.

El resto de materias primas se manifiesta de manera menos significativa, destacando las variedades de sílex, que aparecen en piezas bastante significativas a nivel de conjunto y que está presente tanto en la producción tallada como en la pulida.

A nivel de conjunto, la categoría analítica que aparece representada en un mayor porcentaje es la de las piezas con pulimento de uso, y que está compuesta fundamentalmente por los molinos y sus correspondientes movientes o manos. También importante desde el punto de vista cualitativo es que, dentro de los productos de lascado, en el grupo de los soportes simples, los soportes laminares aparecen igualmente representados que los soportes tipo lasca. El grupo de piezas de otras producciones, y más concretamente el conjunto de fragmentos de cantos es otra categoría bien representada y que, debido al estado de fragmentación que presentan, apenas permiten establecer su implicación en el conjunto. El resto de categorías aparece menos representado, y de mayor a menor, son los desechos de talla, los soportes retocados y los núcleos.

Antes de comenzar a analizar los aspectos que se derivan del análisis de la producción tallada debemos retomar algunos de los ya perfilados en el apartado metodológico.

Tal y como ya se ha planteado, la identificación de caracteres tecnológicos en el material lítico tallado ha estado siempre ligado al estudio de colecciones líticas realizadas casi exclusivamente en rocas silíceas y de fractura concoidea, así como a una tradición tipológica y al empleo de estos tipos como indicadores cronoculturales. Esta casi exclusividad de las rocas silíceas ha provocado que no se le haya prestado demasiada atención al comportamiento y a las consecuencias derivadas de la aplicación de las técnicas de talla a las diversas y variadas litologías que encontramos en las colecciones líticas arqueológicas, y más concretamente en el caso gallego. Y es este vacío de información lo que ha provocado el descarte de material lítico que, siendo de factura antrópica, no encajaba en ninguna de las categorías y tipos descritos en la bibliografía.

El cuarzo supone casi el 99\% del soporte litológico de la producción tallada de las colecciones líticas recuperadas en los yacimientos gallegos, si bien, hasta hace unas décadas, bien por desconocimiento a la hora de identificar los atributos tecnológicos en este tipo de materiales, o bien por la preferencia por recuperar otro tipo de piezas, aquéllas tipológicamente reconocibles, este fenómeno no podía ser dimensionado ni valorado. 
En el contexto de la investigación arqueológica gallega, la mayoría de las aproximaciones a los materiales del grupo del cuarzo a un nivel tecnológico se ha centrado sobre todo en las variedades más hialinas (Villar 1991, Llana, 1991), que tienen un comportamiento similar al de las rocas silíceas. Estos autores se han centrado sobre todo en el estudio de las industrias líticas del Paleolítico Superior, planteando a mediados de los años 80 la existencia de una auténtica tecnología del cuarzo en las colecciones y la posibilidad de establecer similitudes y equivalencias con las tipologías tradicionales al uso.

Faltan todavía estudios de carácter experimental con materias primas de carácter local, que permitan establecer cuáles son los rasgos formales y los atributos tecnológicos de los productos resultantes de la aplicación de las diferentes técnicas de talla a este tipo de materias primas.

Una vez anotados estos precedentes, trataremos de establecer algunas de los rasgos tecnológicos que se han podido apreciar como consecuencia del análisis de este conjunto.

La producción tallada del yacimiento de O Regueiriño está representada por un total de sesenta y una piezas, de las cuales cincuenta están realizadas sobre materiales del grupo del cuarzo. A pesar del escaso número de efectivos, aparecen representadas todas las categorías.

La escasa presencia de núcleos supone un importante lastre a la hora de realizar implicaciones a nivel de elecciones tecnológicas y explotación de los mismos. Aun así, intentaremos abordar algunos aspectos.

El primer aspecto se refiere a las materias primas, cuarzo y sílex. Ninguno conserva restos de corteza ni rasgos formales que permitan intuir cual ha sido el tipo de soporte sobre el que se ha realizado la explotación. Los ejemplares de sílex parecen encontrarse en fase de abandono, así como uno de los de cuarzo, y los productos obtenidos sugieren un tipo de explotación que busca soportes de medianas y pequeñas dimensiones, tanto de tipo lasca como laminares. Sin embargo, debemos matizar que esta producción, teniendo en cuenta la escasa representatividad numérica de la muestra, no parece estar orientada hacia una estandarización de soportes ya que aparecen morfologías y tipometrías heterogéneas.

Los productos de lascado aparecen bien representados en el conjunto, de nuevo con predominio del cuarzo. Como ya se ha comentado, la presencia de formas prismáticas es bastante significativa en todo el conjunto, y aparecen representadas en la mayoría de las categorías tecnomorfológicas definidas, desde las que aparecen sin huellas de modificación, las que presentan algún negativo de extracción, hasta soportes simples y restos de talla que conservan parte de superficie cortical prismática. Destacan además los soportes retocados realizados también sobre soportes 
prismáticos, aunque en estos casos estos soportes han tenido que ser de mayor envergadura a los conservados completos, teniendo en cuenta el espesor que alcanzan estas piezas.

Sobre este tipo de piezas, existe cierta controversia para definir si se trata propiamente de útiles o bien de núcleos para extracción de laminillas. F. Fabián planteó ya esta cuestión para un conjunto significativo del yacimiento paleolítico de La Dehesa, en Salamanca. Este autor ha definido la existencia de una serie de útiles realizados sobre prisma y que ha denominado útiles de arista diédrica, U.A.D. Para este autor, la diferencia fundamental entre los núcleos y este tipo de útiles radica en el tipo de extracciones existentes en uno y otro, ya que «mientras en los núcleos son siempre productos laminares, en los U.A.D., son, generalmente, lascares» (Fabián 1984: 118-119).

La documentación de formas prismáticas es un hecho bastante recurrente en contextos megalíticos. Para el caso del NW, R. Fábregas (1991) ha recopilado los datos referentes al registro de estas piezas, documentados en trece yacimientos, y con la noticia de aparición en, al menos, diez yacimientos más, sobre todo en el territorio gallego. La mayoría de estas piezas no poseen huellas de modificación antrópica, excepto la existencia de fracturas en la zona de la base, como consecuencia de su extracción del soporte original.

Este autor recoge las diferentes interpretaciones que la aparición de estas formas ha suscitado entre los diferentes investigadores, desde una aparición casual debida a su existencia en el propio sustrato empleado para construir el monumento, a una deposición intencional como ajuar o su asimilación a propiedades de tipo mágico o ritual (Fábregas 1991: 203).

La ausencia de huellas de modificación en la mayoría de los prismas documentados en estos yacimientos no permite realizar inferencias tecnológicas o funcionales claras; sin embargo, en otras zonas de la Península sí se han documentado piezas prismáticas retocadas conformando filos cortantes (Fabián 1984, 1986 y 1997; García Gazólaz, J. y Velaz Ciáurriz, D. 1997). Lo que sí apunta este autor es que, a pesar de que en Galicia no se hayan documentado estas evidencias, el empleo de formas prismáticas como materia prima sí se ha constatado, como es el caso de un ejemplar de lámina localizado en el dolmen de Cova da Moura (Argalo, Noia) y que conserva córtex prismático en la cara dorsal (Fábregas 1991: 204). Otro dato interesante es el de la documentación de este tipo de soportes prismáticos retocados en contextos domésticos, coetáneos al fenómeno megalítico, en el norte de Portugal (Jorge 1986, en Fábregas 1991: 204).

Si bien para el fenómeno megalítico el empleo de formas prismáticas como soporte para la producción de instrumentos no acaba de estar claro, este hecho sí ha 
sido constatado por algunos autores para épocas más antiguas de la prehistoria de Galicia, como es el Paleolítico Superior y Epipaleolítico (Villar 1991, Llana 1991), o para el mismo período en la zona de la meseta, tal y como se ha comentado para el caso de los U.A.D. (Fabián 1984, 1986 y 1997).

Esta imprecisión tecnológica a la hora de discernir entre uno u otro tipo haría necesaria una contrastación de los datos con base en un estudio de carácter funcional para poder llegar a precisar si este tipo de piezas han sido empleadas o no.

En cuanto a la representatividad de los soportes retocados, podemos destacar aquellas piezas que presentan cierta homogeneidad formal y tecnológica, que presentan un filo agudo que insinúa un uso cortante. Sin embargo, este extremo no podría ser confirmado sin un análisis de trazas de uso. Esta repetición de morfologías en los soportes retocados, y con la cautela del escaso número que estas piezas representan, podría interpretarse como un signo de la especialización de actividades en el yacimiento.

A nivel tecnológico, dentro de la producción tallada hemos anotado algunos rasgos que podrían relacionarse con el empleo de la técnica de talla bipolar apoyada sobre yunque, una de las técnicas que por fortuna ha sido abordada por algunos autores del continente americano, analizando de forma detallada las implicaciones del uso de esta técnica sobre el cuarzo, así como los soportes obtenidos a partir del empleo de la misma mediante trabajos experimentales (Prous 1986/1990, Curtoni 1996).

En cuanto a la producción pulida, destaca la documentación de un abundante número de piezas de molienda, esto es, de molinos y movientes. El sustrato granítico de la zona en la que se ubica el yacimiento podría haber facilitado todos los soportes necesarios para estos objetos sin necesidad de invertir demasiado tiempo en su abastecimiento. Si bien los movientes comparten la particularidad de haber sido cantos rodados naturales reaprovechados, la variedad morfológica de los molinos que se conservan enteros no permite plantear la predilección por una morfología determinada.

Por lo que se refiere a las otras piezas analizadas dentro de la producción pulida, sólo mencionar el estado de fragmentación del único instrumento con pulimento de fabricación y no de uso. Tal y como ya se ha tratado en el apartado correspondiente, su asignación a un tipo u otro no ha podido ser aclarada, si bien no creemos que sea un aspecto fundamental. Un análisis petrológico que nos indicase el posible origen de la materia prima empleada, o bien un análisis de trazas de uso que permitiese realizar inferencias funcionales, permitirían el establecimiento de otros aspectos que en este nivel de análisis se nos escapan.

Falta entonces un estudio de carácter integral y multidisciplinar, ya que, como adelantamos en el apartado metodológico, el estudio de las colecciones líticas debe- 
ría ser abordado desde diversas perspectivas de análisis, desde la gestión y empleo de las materias primas hasta el abandono de la muestra y la implicación de los procesos deposicionales en la misma.

Acometido por tanto el análisis de morfologías y caracteres tecnológicos de este conjunto, la posibilidad de ampliar los resultados a otro nivel de implicación y de resultados queda abierto para futuros trabajos.

Resulta bastante obvio plantear que en el Neolítico, a nivel tecnológico y dentro de la cultura material, se producen dos importantes avances; por un lado la aparición de la cerámica y por otro el pulido de la piedra. Si bien no vamos a entrar en valoraciones con respecto a la cerámica, sí podemos apuntar algunas para la tecnología lítica.

La aparición de la producción pulida ha sido relacionada tradicionalmente con el momento a partir del cual el trabajo sobre la madera pasa a ser un factor importante dentro de la economía prehistórica; podríamos decir que surge por tanto como consecuencia de necesidades productivas y económicas concretas. A nivel puramente técnico, el pulido permitió la obtención de filos más resistentes, biconvexos, y creando además un resultado estético relevante (Prous 1986/1990: 23).

Para la producción tallada, el neolítico cuenta con una considerable y arraigada tradición, y por tanto, tal y como señala A. Cava (1986: 51), «si la aparición de la cerámica no se acompaña de modificaciones importantes en la industria lítica no es porque se trate de epipaleolíticos superficialmente neolitizados sino porque la mutación verdadera y profunda ya había tenido lugar antes».

Plantear y asimilar la significación del conjunto lítico recuperado en el yacimiento de O Regueiriño dentro de un contexto neolítico más amplio para la región del noroeste peninsular, resulta una tarea bastante complicada teniendo en cuenta la escasez de excavaciones de los yacimientos que se conocen para este período y por tanto la inexistencia de estudios sistemáticos de colecciones líticas.

Las actuaciones arqueológicas y las publicaciones que se han derivado de los trabajos previos que se han llevado a cabo en este yacimiento han apuntado una cronología que lo sitúa en los inicios de IV milenio a.C. Sin intención de afinar en la misma, y a la espera de los resultados de las dataciones radiocarbónicas que se realicen, parece claro adscribirlo cronoculturalemnte al Neolítico Inicial/Medio (Suárez 1997).

Actualmente, el elenco de yacimientos adscritos a este período en Galicia es bastante significativo, aunque los análisis de la cultura material se han centrado casi exclusivamente en la cerámica, haciéndose apenas algunas escasas referencias a los materiales líticos documentados (Peña 1985, Suárez 1997:490). Además, estas referencias se han centrado casi de manera exclusiva en aquellas piezas más signi- 
ficativas, las tipológicamente identificables, que son las piezas retocadas y pulimentadas.

Esperamos por tanto que este análisis sirva como punto de partida para poder empezar a aportar más datos acerca de las actividades productivas de las comunidades prehistóricas, y de cómo esta parte, muchas veces obviada, de la cultura material, puede contribuir a establecer interpretaciones que pueden ir más allá de lo que, a priori, se le ha atribuido.

\section{Agradecimientos}

Teniendo en cuenta que los procesos de trabajo en esta disciplina casi siempre corresponden a un esfuerzo conjunto, el agradecimiento ha de ser en primer lugar de carácter plural. A Adro Arqueolóxica por habernos permitido acceder al análisis de esta colección, a mis compañeras del Laboratorio de Cultura Material y por extensión, a todo el equipo de compañer@s del Laboratorio de Arqueoloxía da Paisaxe (IEGPS, CSIC-XuGa). Pero también individual, a Anxo Rodríguez por su perfección gráfica, a Xavier Terradas, Pilar Prieto y César Parcero por la revisión crítica del texto y a Felipe Criado, por ser el responsable de este esfuerzo conjunto.

\section{BIBLIOGRAFÍA}

FÁBREGAS VALCARCE, R., 1984: La industria de piedra pulida en las sepulturas megalíticas de Galicia. Trabajos de Prehistoria, 41:129-163. Departamento de Prehistoria de la Universidad Complutense de Madrid.

FÁBREGAS VALCARCE, R., 1991: Megalitismo del Noroeste de la península Ibérica. Tipología y secuencia de los materiales líticos. Madrid: U.N.E.D.

CAVA, A., 1986: La industria lítica de la Prehistoria Reciente de la Cuneca del Ebro. Boletín del Museo de Zaragoza. Bol. 5:5-72. Zaragoza.

CRIADO BOADO, F. y CABREJAS DOMÍNGUEZ, E. (coord), 2005: Obras públicas e Patrimonio. Estudo arqueológico do Corredor do Morrazo. TAPA (Traballos de Arqueoloxía e Patrimonio) n. ${ }^{\circ}$ 35. Santiago de Compostela. Instituto de Estudos Galegos Padre Sarmiento. CSIC-XuGa.

CURTONI, R. P., 1994: La experimentación en arqueología. Estudio de la técnica de reducción bipolar en la localidad arqueológica Tapera Moreira, cuenca del río Curacó, prov. de la Pampa. Tesis de licenciatura, Facultad de Filosofía y Letras de la Universidad de Buenos Aires.

CURTONI, R. P., 1996: Experimentando con bipolares: indicadores e implicaciones arqueológicas. Relaciones de la Sociedad Argentina de Antropología, XXI:187-214. Buenos Aires.

CURTONI, R. P., 1996: Aprovisionamiento de materia prima y técnica de reducción bipolar en un ambiente semidesértico. III Jornadas de Arqueología de la Patagonia, mayo de 1996. San Carlos de Bariloche, Argentina. En prensa. 
FABÍAN, F., 1984-1985: Los útiles de arista diédrica sobre prismas piramidales o nódulos de cristal de roca (U.A.D.) en el yacimiento de La Dehesa, El Tejado de Béjar (Salamanca). El estudio morfotécnico. Zephyrus, XXXVII-XXXVIII: 115-124. Salamanca.

FABÍAN, F. ,1986: La industria lítica del yacimiento de $<<$ La Dehesa $>>$ en el Tejado de Bejar (Salamanca). Una industria de topología magdaleniense en la meseta. Avance a su estudio. NUMANTIA. Investigaciones Arqueológicas en Castilla y Léon, II: 101-141. Museo de Salamanca.

FABÍAN, F., 1997: La difísicil definición actual del Paleolítico Superior en la Meseta. El yacimiento de La Dehesa (Salamanca) como exponente de la etapa magdaleninese Final. II Congreso de Arqueología Peninsular. Tomo I: 219-237. Zamora, del 24 al 27 de septiembre de 1996. Eds. R. De Balbín, P. Bueno Ramírez. Fundación Alfonso Enriques.

GARCÍA GAZÓLAZ, J. y VELAZ CIÁURRIZ, D., 1997: La industria lítica tallada de las primeras comunidades neolíticas en la cuenca de Pamplona (Navarra): el caso del cristal de roca. Cuadernos de Arqueología, 5: 7-29. Universidad de Navarra.

I.G.M.E., 1981: Mapa geológico de España, E. 1:50.000. Hoja 223 (4-11) (Vigo). Servicio de Publicaciones Ministerio de Industria y Energía. Segunda serie-Primera Edición.

LAPLACE, G., 1972: La typologie analytique et structurale: Base rationnelle d'étude des industries lithiques et osseuses. Banques des données archéologiques. Colloques nationaux du CNRS 932: 91-143.

LLANA, C., 1990: Algunas consideraciones económicas del Paleolítico Superior a través de los cuarzos y cuarcitas de grano grueso. Gallaecia, 12: 29-37. Departamento de Historia I. Universidad de Santiago de Compostela.

MERINO, J. M., 1980: Tipología Lítica. Munibe, suplemento 4. San Sebastián.

MORA, R., TORCAL, J., TERRADAS, X., 1992: Un proyecto de análisis lógico: el sistema lógico analítico (SLA). En Tecnología y Cadenas Operativas Líticas. Treballs d'Arqueologia, 1:173-199. Ed. Deperatament d’História de les Societats Pre-capitalistes i d’Antropologia Social de la U.A.B. Barcelona.

PEÑA SANTOS, A. de la, 1985: Sondeo estratigráfico en el yacimiento de «O Regueiriño» (Moaña). Pontevedra Arqueológica, I: 85-90. Pontevedra.

PRIETO P., TABARÉS M. y BAQUEIRO S., 2005: Estudo da cultura material de A Devesa de Abaixo-Os Torradoiros. En Criado Boado, F. (coord). Obras públicas e Patrimonio. Estudo arqueológico do Corredor do Morrazo. TAPA (Traballos de Arqueoloxía e Patrimonio) n. ${ }^{\circ} 35$. Santiago de Compostela: Instituto de Estudos Galegos Padre Sarmiento. CSIC-XuGa.

PRIETO P., TABARÉS M. y BAQUEIRO S., 2005a: Estudo da cultura material do xacemento de O Regueiriño. En Criado Boado, F. (coord). Obras públicas e Patrimonio. Estudo arqueológico do Corredor do Morrazo. TAPA (Traballos de Arqueoloxía e Patrimonio) n. ${ }^{\circ} 35$. Santiago de Compostela: Instituto de Estudos Galegos Padre Sarmiento. CSIC-XuGa.

PROUS, A. y ALONSO LIMA, M., 1986/1990: A tecnología do quartz no centro de Minas Gerais: lascamento bipolar. Arquivos do Museu de História Natural. Universidade Fegeral de Minas Gerais. Belo Horizonte. V.11 pp: 91-111.

PROUS, A., 1986/1990: Os artefactos líticos, elementos descriptivos clasificatorios. Arquivos do Museu de História Natural. Universidade Fegeral de Minas Gerais. Belo Horizonte. V.11, pp: $1-88$. 
SEMENOV, S. A., 1981: Tecnología prehistórica: estudio de las herramientas y objetos antiguos a través de las huellas de uso. Akal. Madrid.

SUÁREZ OTERO, J., 1997: Del yacimiento de A Cunchosa al neolítico en Galicia. Primera aproximación al contexto cultural de la aparición del megalitismo en Galicia. En A. Rodríguez Casal (ed.). O Neolítico Atlántico e as orixes do megalitismo: 485-506. Santiago de Compostela: Universidade de Santiago de Compostela.

SUÁREZ OTERO, J. \& FÁBREGAS VALCARCE, R., 2000: O Neolítico en Galicia. Estado da cuestión. Neolitizaçâo e megalitismo da Península Ibérica. Actas do 3.er Congreso de Arqueologia Peninsular (septembro 1999, Vila Real Portugal), vol. III: 135-47. Porto: ADECAP.

TABARÉS M. y BAQUEIRO, S., 2005: Estudo da cultura material de Montenegro. En Criado Boado, F. (coord). Obras públicas e Patrimonio. Estudo arqueológico do Corredor do Morrazo. TAPA (Traballos de Arqueoloxía e Patrimonio) n. ${ }^{\circ}$ 35. Santiago de Compostela: Instituto de Estudos Galegos Padre Sarmiento. CSIC-XuGa.

TERRADAS BATLLE, X., 1995: Las estrategias de gestión de los recursos líticos del prepirineo catalán en el IX milenio BP: el asentamiento prehistórico de la Font del Ros (Berga, Barcelona). Treballs d'Etnoarqueología, 3. Ed. Deperatament d’História de les Societats Pre-capitalistes i d’Antropologia Social de la U.A.B. Barcelona.

TERRADAS BATLLE, X., 2001: La gestión de los recursos minerales en las sociedades cazadorasrecolectoras. Treballs d’Etnoarqueología, 4. Ed. CSIC. Madrid.

VILA, A., 1987: Introducció a l'estudi de les eines lítiques prehistóriques. Consejo Superior de Investigaciones Científicas y Universitat Autónoma de Barcelona, Barcelona.

VILLAR, R., 1990: Algunas consideraciones sobre el tratamiento técnico de los cuarzos presentes en yacimientos del Paleolítico Superior de Galicia y Asturias. Características de estos soportes. Gallaecia, 12:39-49. Departamento de Historia I. Universidad de Santiago de Compostela. 
